\title{
Application of Knowledge Management in E-Governance: A Case Study on Internet based Data Base Management
System from India
}

\author{
Lipsa Sadath \\ Dept. of Computing \\ Muscat College \\ Muscat, Sultanate of Oman
}

\author{
Madhuri V. Joseph \\ Dept. of Computing \\ Muscat College \\ Muscat, Sultanate of Oman
}

\author{
Silpa Sagheer, PhD. \\ Former Senior Assistant Director \\ (Food Processing Division) \\ $\mathrm{FICCl}$ \\ New Delhi, India
}

\begin{abstract}
In the prevailing information technology era, a typical definition of 'knowledge management' as a concept focuses on creating, managing, utilizing, communicating and sharing knowledge. In this context, this paper aims to examine the significance of Knowledge Management systems in enhancing agrifood exports in a developing country like India. The country has successfully developed and implemented complete traceability systems for its fresh grape exports as part of an E-Governance initiative. The study examines and compares a few typical Knowledge Management models in connection with the Data Base Management System focusing Grapenet - an internet based traceability software system for fresh grapes exported from India to the European Union. The software is designed to reach at the root of any grape export transaction. The model chosen to explain the case study is the conceptual model of E-Government using Knowledge Management. The success achieved in implementing the pesticide residue monitoring system and IT based traceability procedure has enabled all stakeholders viz. farmers, exporters etc. in India and importers in the EU to develop confidence in Indian grape sector and its quality. The model's major focus is on the use of knowledge management as an internal part of EGovernment system. The establishment of 'Grapenet' to run a complete traceability system was critical in the grape export sector. The study recommends the need for integrating knowledge base management system with data base system. The case thus highlights the role of EGovernance as a key enabler in trade enhancement and interaction in international markets for developing countries.
\end{abstract}

\section{Keywords}

Knowledge Management, E-Governance, Traceability, Agrifood, Grapenet

\section{INTRODUCTION}

Data Management, a core component of Knowledge Management deals with processes and behaviors of people to transform information and create and share knowledge. On a wider plane, "Knowledge Management" (KM) as a concept has been embraced by varied users in domains ranging from public administration to systems development. The focus is on creating, managing, utilizing, communicating and sharing knowledge. Electronic-Governance or E-Governance has developed in recent years as a critical element for providing good governance through applications of Information and Communication Technology (ICT). KM as a tool for better realization of E-Governance has been explored very effectively by various governments and related public bodies and organizations in recent years.

This paper is a case study examining the use of Knowledge Management through E-Governance for a business oriented transaction between export grape sector and government of a developing country like India. A conceptual model of EGovernment [1] based on Knowledge Management (KM) is used to fit the case study. The paper is divided into seven sections. Section one is introduction, section two explains EGovernance definition and role in a developing country and section three is on traceability and its relevance to food industry and a developing country. Section four explains the selection of the model for case study, section five is model used for case study, rationales for choice, a future proposal for the use of expert system - a component of Artificial Intelligence in databases and knowledge management systems and section six is conclusion.

\section{E-GOVERNANCE: DEFINITION AND ROLE IN A DEVELOPING COUNTRY}

Governments across the world have turned towards EGovernance realizing its potential as a powerful application cutting across massive structures and layers of information relating to governance. Literature review revealed no standard definition of the term "E-Governance" although it has been widely referred to in a range of contexts. Each agency and organization defines the term adapting it to their roles and objectives in public sphere, sometimes even interchangeably using the term "E-Government" for "EGovernance".

A Government of India (GoI) Report released by Second Administrative Reforms Commission of India, 2008 [2] presented various definitions in use for the term "EGovernance". Among those, the definition given by World Bank seems most fitting to the context of this paper, wherein it is defined as "the use by government agencies of information technologies (such as Wide Area Networks, the Internet, and mobile computing) that have the ability to transform relations with citizens, businesses, and other arms of government." These technologies can serve a variety of different ends such as better delivery of government services to citizens, improved interactions with business and industry, 
etc. The major focus for the government through EGovernance has been on addressing transparency issues in their bureaucracies and making themselves more responsive to their citizens by involving people in administration. This helps in faster decision making, handling of data redundancy, detection of corruption and illegal transactions, thus helping public sector business to reach common man [3].

The challenges and success rates of E-Governance in developing countries have been researched by various researchers. Reference [4] explored the possibilities of enhancing E-Government application in developing countries by managing virtual communities. Reference [5] discussed the legal and infrastructural issues in implementing E-Governance in a developing country. Reference [6] looked at the institutional and cultural issues to be considered while implementing E-Governance in subSaharan Africa.

The common trend of focusing on management areas alone was questioned by Reference [7], who felt E-Governance should be explored as a tool in several other areas of government functioning, policy making being a case in point. E-Governance has also found use in government to business transactions. E-taxation is one such example followed by several countries including India. In developing countries like India the issues in putting in place EGovernance mechanisms are discussed in terms of standards, public key infrastructure etc. [8]. A recently explored domain in business to government transaction in India with successful results is a "traceability" mechanism for the table grade export sector. Implemented by Agricultural and Processed Food Export Development Authority (APEDA), the export development agency of the Government of India, the internet based operation is called "Grapenet".

\section{TRACEABILITY:ITS RELEVANCE FOR FOOD INDUSTRY AND A DEVELOPING COUNTRY}

The term traceability refers to recording of flow of products along the food chain from production to consumption with inclusion of all intermediate applications involved in processing/packaging stages [9]. The Webster's dictionary defines traceability as "the ability to follow or study out in detail, or step-by-step, the history of a certain activity or process". Codex Alimentarius Commission, the apex body for formulating international food standards defines food traceability as "the ability to follow the movement of food through specified stage(s) of production, processing and distribution" [10].

The concept has gained much relevance in global food supply chains finding acceptance in developed countries where the systems and processes for the same has been laid out and compliance ensured [11]. Developing countries exporting to developed countries have been feeling the pressure to implement traceability [12]. India's fresh table grape exports had been facing this challenge following detection of high pesticide residue in some consignments to the European Union.

\section{SELECT MODELS OF E- GOVERNANCE}

Basically E-Governance can be considered as a government which uses internet facilities to provide improved and better accessibility of public services .The primary E-Government delivery model can be divided into four namely Government-to-Business, Government-to-Consumer, Government-to-Government and Government-toEmployees. [13]. According to the interactive service models information technologies have the potential to bring in every individual in a digital network and enable interactive (two-way) flow of information amongst them. The potential of the governance is fully leveraged in the model. The broadcasting model is based on broadcasting or dissemination of useful governance information using ICT and convergent media. The utility of this model is that citizens are more informed about the benefit from governance related services. The model is based on broadcasting information of 'critical' value to targeted audience using ICT and convergent media. The model is the concept of that the 'distance' and 'time' becomes redundant when information is hosted on a digital network [14]. A model of E-Governance based on KM is a path based process which provides an environment in the system grows with people [3]. The conceptual model of E-Government [1] using knowledge management incorporates Knowledge acquisition, organization, distribution and application in an E-Government system.

\subsection{Model Used For Case - Study and Rationale for Choice}

The model chosen to explain the case study is the conceptual model of E-Government using Knowledge Management [1]. The model's major focus is on the use of knowledge management as an internal part of E-Government system as in the Figure (Fig. 1.) below. This model discusses the knowledge management for E-Government development in the needs and role. It focuses on analyzing the advantages of using knowledge management by using the existing IT technologies to maximize the government functions efficiency. The proposed new approach of providing government services is based on using Knowledge management. Application of appropriate technologies by government, based on the various stages will then work towards maintaining and using knowledge to facilitate its functions. This needs to be carried out by taking into consideration the nature of government's work as compared to functions of other organizations. Life-cycle stages when combined with knowledge management portal can become a very powerful tool for E-Governance. The portal will be critical to process structured and unstructured information through extraction, analysis and categorization. E-mail, chat rooms, feed backs etc. are critical facilities in this context.

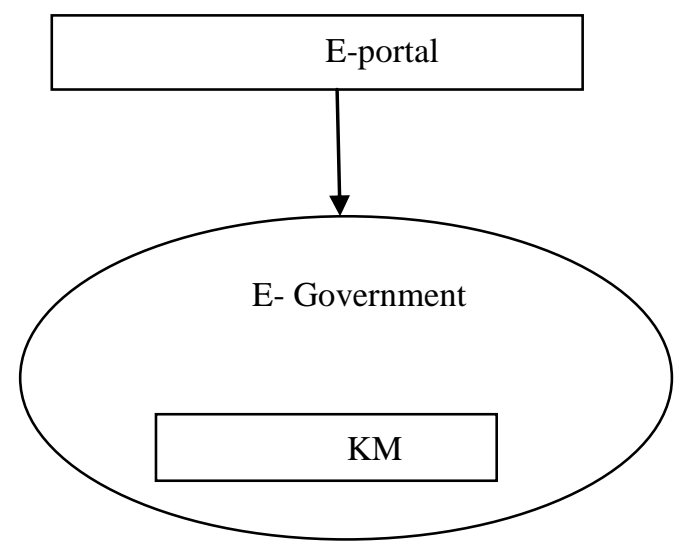

Fig.1. Conceptual Model of E-Government [1] 
The e-portal of the Grapenet system blends with the conceptual model to present the user with web services that brings together or aggregates content from a number of other systems or servers. The Grapenet portal server is in reality only a front piece of a server configuration that includes some connectivity to the application server. Further the Export Development agency (E-Government) makes use of Knowledge management which includes various stages of the framework.

\section{THE CASE -STUDY: E - GOVERNANCE AS AN EFFECTIVE TOOL FOR TRACEABILITY}

The case study presented is on Grapenet (Fig. 2.)[15] - an internet based traceability software system for fresh grapes exported from India to the European Union. This was initiated by Export Development Agency entrusted with exports of agricultural and processed food under the Government of India in 2006-07 in the Indian fresh produce sector. The objective of Grapenet is to establish an end-toend pesticide residue monitoring system, achieve product standardization and facilitate tracing back of the produce from retail shelves to the farm of the Indian grower, through multi stage activities of sampling, testing, certification and packing. The application of this system starts at the very first stage of registration of farmers at plot level, in district headquarters, by the State Government Agency (SGA) of state horticulture departments and subsequently issuing a registration certificate to the farmers. Each plot is identified by a unique 12 digit registration number and tested for pesticide residues. Exporters can only source produce from the plots of the farmers whose samples pass through these tests. Before proceeding for their inspection, the laboratories use the online system to generate a unique Agmark Inspection ID for each lot to be inspected and this ID is pasted on the pallet of grapes. Agmark standards are grade standards prescribed for agricultural and allied commodities under the Agricultural Produce (Grading and Marketing) Act, 1937 and enforced by the Directorate of Marketing and Inspection, Ministry of Agriculture, Government of India. Only those lots are accepted by the system that has passed the residue tests for the destination country. After this inspection, a Certificate of Agmark Grading(CAG) or CAG ID is created by the laboratories, listing out the individual Agmark Inspection Report IDs covered under them for this particular consignment of an exporter. AGMARK office issues AGMARK certificate or CAG to the exporter based on this, through this integrated software. The plot number of farmer and exporter registration number are all linked at this stage to the Agmark Inspection ID and to the CAG ID.

The next in the chain are the Phyto-Sanitary Departments (PSD) at district level who carry out verification of the consignment at the registered pack houses and issue PhytoSanitary Certificates (PSC) through this system. CAG issued in the previous stage is mandatory for the issue of PSC. The system goes through a 360 degree evaluation procedure for the consignment to be declared fit and ready for shipment [16].

This approach for modeling to establish traceability through Grapenet is an attempt to manage related government information resources effectively in e-business which facilitate the retrieval of information through E-Government business system for the users. Analysis and sharing enables better government services, thereby enhancing the image of the government's need for the E-Government construction and development of KM and resource sharing.

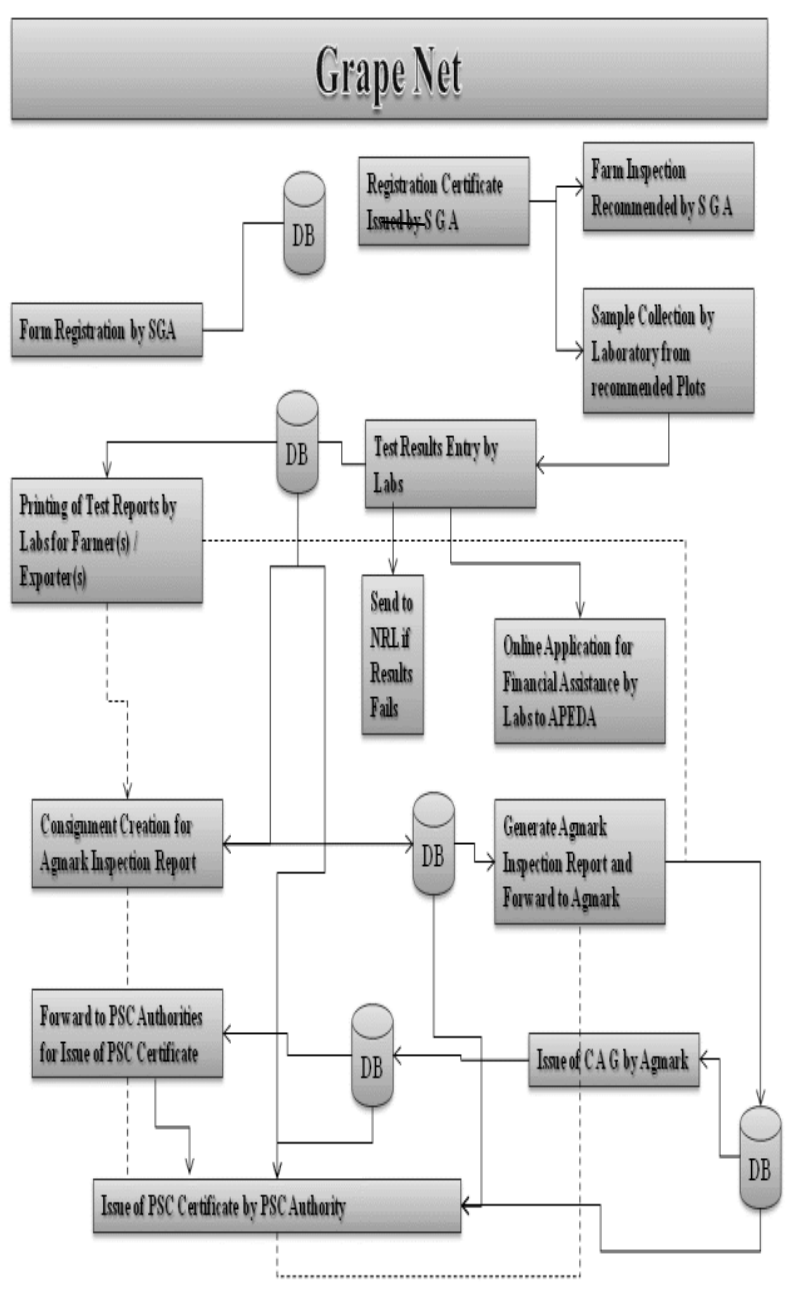

Fig.2. Grapenet system of APEDA [15]

SGA-State Government Agency, Labs- Laboratories accredited by export development agencies, DB-Data Base, NRL-National Referral Laboratory, PSC- Phyto- sanitary Certificate.

The case study is an attempt to understand the E-Governance mechanism set up through 'Grapenet', an internet based software for enhancing fresh table grapes exports from India. A conceptual model of E-Government [1] based on KM is used for the purpose. Here each stage can be identified through the model where farmers register with the SGA initially till the last stage of certificate issuing by PSC authority and Agmark which covers knowledge creation, knowledge organization/storage, knowledge distribution and knowledge application. The system focuses on enabling one to trace back for finding out the cause of a problem and preventing it from happening again.

KM centers mainly on the creation, organization and sharing of knowledge. The model implies that those organizations best positioned to collect, index, and store and analyze 
knowledge have an advantage over their competitors. With knowledge management, systems are put in place to collect the answers and make them more accessible. This approach can be used anywhere in E-Governance but most often makes sense in customer support applications.

The Grapenet system depends on a centralized database in which the SGA enters information about the plot that leads subsequently to the various stages of sampling, testing, certification and packing. The Grapenet centralized database integrates all stakeholders in the supply chain of grapes export namely farmers, state governments, horticulture departments, testing laboratories, Agmark certification department, the Phyto-Sanitary department, pack houses, exporters and APEDA.

As per the model the theoretical aspects that will be discussed in this paper are KM framework, KM technology, $\mathrm{KM}$ process, $\mathrm{KM}$ development and $\mathrm{KM}$ lifecycle.

\subsection{KM Framework}

According to the model [1], knowledge management is managing the organization's knowledge through systematic and specified processes for acquiring, organizing, sustaining, applying, sharing and renewing both tacit and explicit knowledge to enhance the organizational performance and create value. It is seen as the systematic means of managing individual, group and organizational knowledge using the appropriate means and technology at the appropriate situation. The model considers the framework to be an allencompassing feature for creating/ generating, coding, storing, disseminating and implementing knowledge.

In the case study, Grapenet is an end-to-end system for monitoring pesticide residue, achieving product standardization and facilitating tracing back from retail shelves to the farm of the Indian grower, through the various stages of sampling, testing, certification and packing. The whole process builds ups a mechanism whereby information generated is coded and stored to be disseminated as knowledge. Thus the details of the final product can be traced back to the plot level. As mentioned in the model the appropriate technology is used by the system which is a 24 by 7 facility accessible to all authorized stakeholders.

\subsection{KM Technology}

The model's technology perspective of KM focuses on collecting, sorting, storing, and sharing the knowledge throughout the organization. On the basis of this perspective, some of the technologies that can be used in the development of KM systems are: intranet, information retrieval engines, groupware, database management systems, data warehousing and data mining, document management system, push technologies, etc.

In the case study the technology used by 'Grapenet' creates a data warehouse that facilitates storing of large number of transactions involved in supply chain management in a demoralized form into a data warehouse. This is then made available using a simple, uniform interface for various users on the intranet and extranet. Grapenet uses dynamically generated web pages, active server applications; encryption components and high-performance databases implementable on a fault-tolerant, highly scalable distributed Relational Data Base Management System. It requires java-enabled browser as well.
Grapenet utilizes standard internet protocols and technologies (TCP/IP, HTTP, HTML, ASP, Java, Search engines, etc.). It has been specifically designed to allow government ministry organizations to connect officials and enable them to access organizational resources using standard internet browsers, cutting costs and enhancing productivity. The framework is secure with security components implemented at several levels using user administration, access rights control, encryption and decryption and activity logs as well.

\subsection{KM Process}

To track and analyze KM system's process, reporting utilities are used. Such reporting tools also help generate knowledge for E-Governance and manage existing knowledge assets. Knowledge management systems emphasis on identifying knowledge sources, knowledge analysis and managing the flow of knowledge within an organization by providing access to knowledge stores as well.

Knowledge management systems are using XML can transport and store data in order to identify and extract knowledge both in and out of the organization as used in Grapenet. The system incorporates Traceability links using XML technologies in an efficient manner.

\subsection{Knowledge Management Development}

KM development involves determining the organization's knowledge needs which is driven by the nature of the business, current state of organizational knowledge base or memory. This provides a status of where and how the organization's current knowledge is assimilated and disseminated. KM helps to determine the gaps in knowledge and barriers to organizational learning which further develops implements and improves proactive strategies.

In Grapenet the details collected at each stage are stored in database common repositories currently where knowledge is collected at a final stage. The knowledge needs, current state, knowledge assimilation and dissemination, concept of resource sharing are brought out clearly through the Grapenet structure. Data mining used in the development process refers to specialized tools that enable us to organize and convert increasingly complex data simple.

\subsection{KM Life Cycle}

The life cycle consists of five phases namely origination/creation of knowledge, capturing/acquiring of knowledge, and transformation/organization of knowledge, deploying/accessing knowledge, and application of knowledge. As per the selected model this knowledge life cycle is depicted in the simplified way, as it suggests a strict sequence of identifying, creating, transferring, storing and (re)-using knowledge.

In the case study the Grapenet system goes through all the phases of the life cycle model wherein the farmer gets registered through the SGA and then goes through a series of plot tests. The results are then entered, organized, distributed through the database, used for certificate attestation by the PSC and Agmark and later on used by the importer to trace back to the plot level. In the Grapenet system knowledge is 
applied by the stakeholders associated to the system on completion of the life cycle process.

The Grapenet system of traceability in E-Governance works according to the conceptual model of KM. The system has a network that links widely the producers and exporters, testing authorities, certificate issuing authorities and the customers (importers) through the software.

$\mathrm{KM}$ is not just computer and information systems; it embodies organizational processes that seek to augment the creative, intelligent, and innovative capacity of human beings. The use of expert systems of artificial intelligence and knowledge base is an integral component of knowledge management systems. This helps to optimize collection, organization, and retrieval of information for an organization or for the general public by reducing manual intervention thus improving the quality of the system.

Artificial Intelligence techniques like intelligent agents (software agents) can also be used to help in the search and retrieval methods of knowledge and information in the knowledge management systems. They can help in combining knowledge which would ultimately lead to the creation of new knowledge [17].

Better E-Governance can be established for knowledge management through the use of intelligent systems. Hence the use of expert systems is proposed as the next stage of Knowledge Management for Grapenet. With its wide application in commercial and industrial settings to integrate searching and sorting programs within knowledge database, value-added services needed in knowledge processing are best achieved by AI or Web-based business rules. A transition from a data base system to a knowledge base system at each level would help Grapenet further excel in advising farmers by processing complex queries. According to AT\&T[18] the knowledge base management system employs compositional descriptions which describe information in terms of concepts. A translation component translates compositional descriptions into data base queries that may be retrieved from the data base. The retrieved information can be automatically integrated into the knowledge base. The translated knowledge base management system through AI would work best for Grapenet. (Fig.3.).

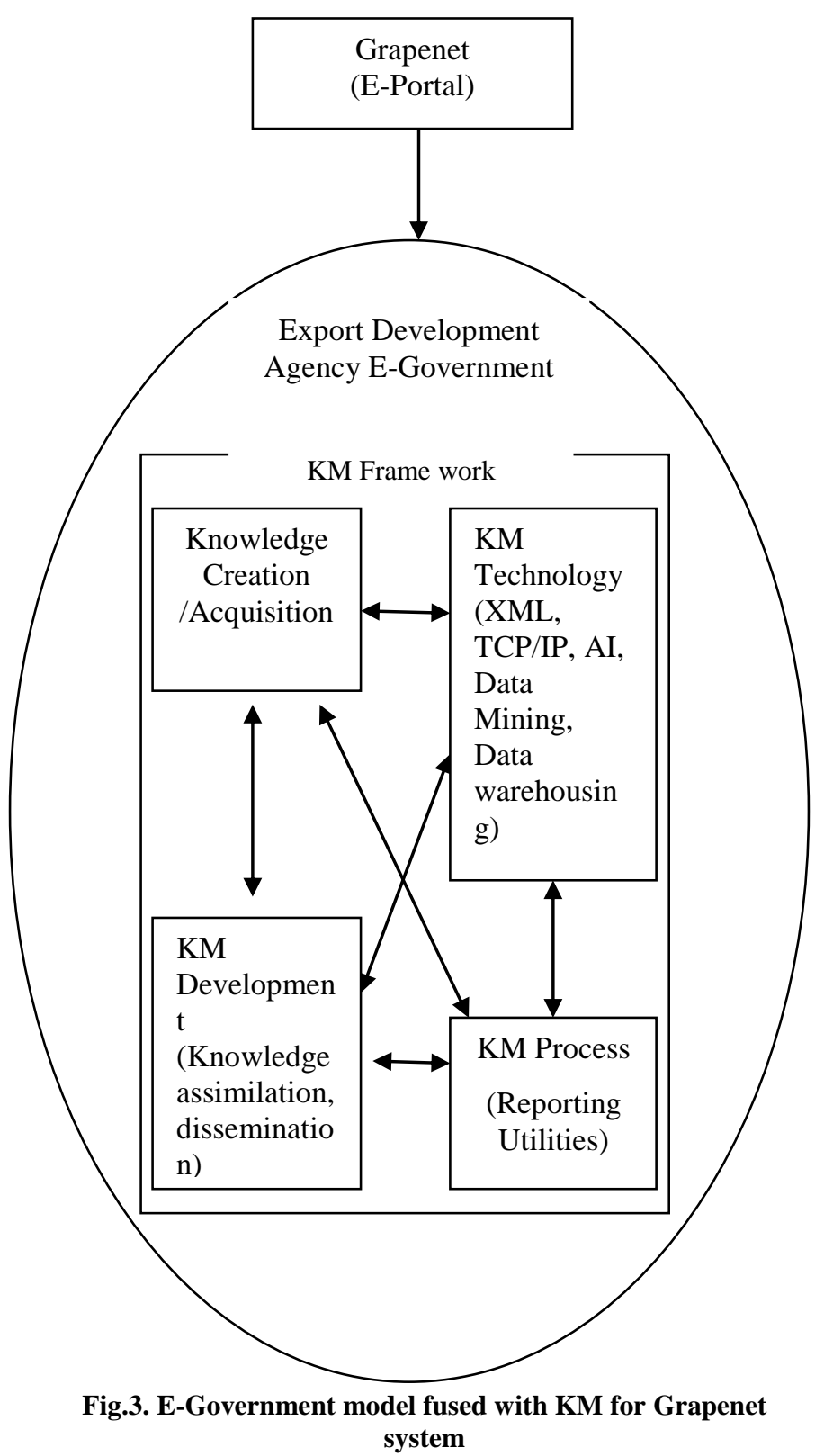

\section{CONCLUSION}

Knowledge management as a part of E-Governance model facilitates the government system to conduct the KM in its environment, and improves the efficiency of government function. Grapenet proved to be a good traceability system presently in collaboration with Knowledge Management and resource sharing in E-Governance environment. Maximizing awareness about KM helps the government gain global advantages. The establishment of 'Grapenet' to run a complete traceability system was critical in instilling customer (importer) confidence and also enhanced their exports. This has further helped in enhancing producer and exporter confidence. The study recommends the need for integrating knowledge base management system with data base system since knowledge bases are much smarter than databases as they process data and use expert knowledge to give expert advice and recommendations. Introducing expert systems would help Grapenet to further improve the mechanism for error handling and robustness to scale up on 
demand and support future applications as complex queries can be processed.

\section{REFERENCES}

[1] Rawajbeh, M. and Ahmed Haboush, Enhancing the eGovernment functionality using Knowledge Management - (World academy of Science, Engineering and Technology 75 2011).

[2] http://arc.gov.in/11threp/ARC_11th_report.htm

[3] Manuel, P., Model of E-Governance based on Knowledge Management, (Journal of Knowledge Management practice, June 2005).

[4] Wagner, C.Cheung, K.S.K., Ip, R.K.F. and Böttcher, S. (2006) 'Building Semantic Webs for e-government with Wiki technology', Electronic Government, Vol. 3, No. 1, pp.36-55.

[5] Basu, Subhajit (2004) 'E-government and developing countries: an overview', International Review of Law, Computers \& Technology, Routledge, part of the Taylor \& Francis Group, Volume 18, Number 1, March 2004 , pp. 109-132(24).

[6] Schuppan Tino(2008), 'E-Government in developing countries: Experiences from sub-Saharan Africa', Institute for e-Government, c/o University of Potsdam, Complex III, August-Bebel-Str. 89, D-14482 Potsdam, Germany.

[7] TORRES LOURDES, VICENTE PINA, BASILIO ACERETE(2006),' E-Governance Developments in European Union Cities: Reshaping Government's Relationship with Citizens', Governance,Volume 19, Issue 2, pages 277-302, April 2006.
[8] Sachdeva Sameer (2002), White Paper on EGovernance Strategy in India', E-Governance Strategy in India'.

[9] Cebeci, Z., Yoldas Erdogan, Tuna Alemdar, Ladine Celik, (Applied Studies in Agro business and Commerce) An ICT based traceability system in compound feed industry.

[10] http://www.fao.org/ag/agn/agns/foodcontrol_traceabilit y_en.asp visited on 30th October, 2011.

[11] Fulponi, L (2006). "Private voluntary standards in the food system: The perspective of major food retailers in OECD countries", Food Policy, Volume 31, Issue 1, February 2006, Pages 1-13.

[12] Frohberg K, Grote U and E Winter EU Food Safety Standards, Traceability and Other Regulations: A Growing Trade Barrier to Developing Countries'.

[13] Anuj Awasthi (2010)- 'E-Governance - Models

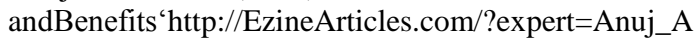
wasthi

Article Source: http://EzineArticles.com/3778198

[14] http://www.digitalgovernance.org/

[15] http://www.lsipl.com/Downloads_page/Grapenet.html)

[16] http://www.apeda.gov.in/apedawebsite/Archive/Grape Net/Features.html referenced on 15th of September, 2011

[17] Sabri Hala AbdulQader 'Making sense of Knowledge Management (KM), Information Technology (IT) and Artificial Intelligence (AI): an Integrative Approach' Asian Transactions on Basic \& Applied Sciences (ATBAS ISSN: 2221-4291) Volume 01 Issue 04.

[18] http://www.patentstorm.us/patents/5418943/fulltext.ht $\mathrm{ml}$ 